Комплекс упражнений

для формирования лингвистической компетенции у китайских студентов музыкального профиля

\author{
Забуга А. А.
}

\begin{abstract}
Аннотация. Цель исследования - разработка комплекса упражнений для студентов-музыкантов из Китая, обучающихся на подготовительных факультетах в музыкальных вузах России. В данной статье рассматривается одна из важных проблем в области методики преподавания русского языка как иностранного - проблема обучения профессионально ориентированной лексике. Научная новизна заключается в попытке создания комплекса упражнений, ориентированного непосредственно на китайскую аудиторию, учитывающего менталитет, культурные и психологические особенности данного этноса и способствующего формированию языковых навыков, а также закреплению профессиональной музыкальной лексики на начальном этапе изучения русского языка. В результате исследования разработан и апробирован комплекс упражнений, направленный на усвоение профессионально ориентированной лексики в китайской аудитории и формирование лингвистической компетенции будущих специалистов.
\end{abstract}

\title{
EN Exercises to Form Linguistic Competence of Students-Musicians from China
}

\begin{abstract}
Zabuga A. A.
Abstract. The research objective includes developing a set of exercises for students-musicians from China at preparation faculties of the Russian higher musical schools. The article discusses one of the key problems in methodology of teaching Russian as a foreign language - the problem of teaching professionally oriented vocabulary. Scientific originality of the study involves developing a set of exercises exclusively for the Chinese audience, taking into account mentality, cultural and psychological peculiarities of this ethnic group. The proposed exercises are focused on forming students' language skills and on enhancing acquisition of professional musical vocabulary at the initial stage of teaching Russian as a foreign language. The research findings are as follows: the author has developed and introduced into educational process a set of exercises aimed to promote the Chinese students' Russian-language professional lexical skills and to form future specialists' linguistic competence.
\end{abstract}

\section{Введение}

В современном мире с увеличением влияния Российской Федерации на мировой арене все больше и больше иностранных граждан из разных стран мира желают получить высшее образование в России. В связи с этим в методике преподавания русского языка как иностранного для обеспечения качественной подготовки новых профессиональных кадров важное место занимает проблема обучения профессионально ориентированной лексике. Анализ научных источников по теме исследования позволил нам констатировать, что в настоящее время существует большое количество наработок для профессиональной подготовки иностранных студентов медико-биологического профиля, экономического профиля, инженерно-технического профиля, естественно-научного профиля, а также будущих лингвистов, математиков, филологов и юристов. Однако в меньшей степени разработаны учебные материалы для профессионального обучения иностранных студентов творческих специальностей, в особенности студентов музыкальных вузов.

На сегодняшний день существуют такие учебные и учебно-методические пособия, как: «Готовимся к профессиональному общению. О русской музыке, Гнесиных, Гнесинке, гнесинцах» [3], «Профессиональное общение музыкантов. Диалог» [4], «Музыкальный калейдоскоп» [5], «Mustermin.ru. Изучаем музыкальные 
термины» [14], «Русский язык как иностранный. Увертюра» [13] и др. Однако данные пособия не подходят для комфортной работы на подготовительном факультете, так как предназначены для более продвинутого уровня владения языком. Конечно, справедливо будет упомянуть и об учебнике под названием «Русский язык для музыкантов» [6], разработанном специально для иностранных студентов музыкальных вузов, только начинающих свое знакомство с русским языком. Тем не менее данный учебник нельзя считать неким идеальным решением, так как он представляет собой лишь сжатый начальный курс русского языка как иностранного и мало отличается от его классических предшественников. Важно помнить, что обучение русскому языку как иностранному без опоры на специфику родного языка студентов, их менталитет и культуру, национальный характер будет неэффективным и не даст должного результата к концу учебного года. Учебник «Русский язык для музыкантов», как и пособия для более продвинутого уровня, кроме «Музыкального калейдоскопа» (предназначенного для обучения китайских студентов Института искусств, владеющих русским языком на уровнях В1 и В2), включает в себя лишь общие методические рекомендации и не является этноориентированным, что, по нашему мнению, представляет существенный минус.

Так, к примеру, при работе со студентами из Китая на подготовительном факультете в условиях ограниченного времени преподавателям-русистам приходится сталкиваться с необходимостью решения конкретных методических задач, связанных со спецификой обучения в китайской аудитории, а также с необходимостью преодоления социокультурного барьера. По мнению профессора Н. А. Спешнева, «мыслительный процесс у китайцев отличают некоторые существенные особенности, корни которых кроются в методах социального воспитания и образовательных требованиях» [15, с. 157]. Именно поэтому при работе со студентами из Китая необходимо помнить, что «китайский этнотип ориентирован на получение знаний о языке как системе, а потом уже на практическое его использование» [2, с. 83].

Из вышеизложенного очевидно, что актуальность нашего исследования продиктована ростом числа китайских студентов, желающих получить высшее образование в музыкальных вузах России; наличием недостатков в уже проведенных исследованиях, а также минимальным количеством качественных этноориентированных методических пособий, терминологических словарей для обучения языку специальности студентов из Китая; необходимостью разработки современного комплекса упражнений для работы с профессионально ориентированной лексикой на подготовительном факультете музыкального вуза в китайской аудитории.

\section{Задачи исследования:}

- проанализировать научно-методическую литературу по теории и практике преподавания русского языка как иностранного в сфере профессионального модуля;

- обосновать и актуализировать необходимость разработки современного комплекса упражнений для работы с профессионально ориентированной лексикой (музыкальный профиль);

- разработать комплекс упражнений, направленный на усвоение профессионально ориентированной лексики и формирование лингвистической компетенции китайских студентов-музыкантов.

Для достижения поставленной цели нами использовались такие методы, как анализ, наблюдение, обобщение, сравнение, описание. В качестве материала исследования послужили устные ответы и письменные работы китайских студентов-музыкантов.

Теоретическую базу исследования составили научные труды современных отечественных и зарубежных лингводидактов (Т. М. Балыхина [2], В. Ван [5], И. А. Пугачев [12], А. Н. Щукин [20], 3. Ф. Юсупова [21] и др.). В своих работах авторы касаются проблем обучения русскому языку иностранных студентов, дают методические рекомендации, рассматривают важность личностно ориентированного подхода на занятиях, учет характера, менталитета, а также языковых и этнопсихологических особенностей китайских студентов. В связи с этим становится ясно, что «аспект “язык специальности” становится ведущим уже на подготовительном факультете и позволяет студентам участвовать в учебном процессе на русском языке, готовит их к занятиям на этапе специализации» [20, с. 159].

Помимо данных работ, мы также проанализировали значительный пласт научно-методической и учебнометодической литературы по теме профессионально ориентированного обучения (Н. А. Агафонова [1], А. И. Лазовская [8], Г. И. Мансурова [9], Н. В. Немченко [10], И. А. Пугачев [12], В. А. Степаненко [16], Е. Ю. Хонг [18], Ю. Чжао [19] и многие др.).

\section{Практическая значимость исследования:}

- разработан комплекс специальных упражнений, направленный на формирование навыков употребления музыкальных терминов студентами-музыкантами из Китая на подготовительном факультете в музыкальном вузе;

- результаты исследования могут быть использованы на практических занятиях с иностранными (китайскими) студентами на начальном этапе обучения русскому языку в музыкальном вузе.

\section{Основная часть}

В музыкальном вузе на подготовительном факультете в условиях ограниченного времени, отведенного на занятия по русскому языку как иностранному, принято вводить музыкальные термины с самых первых уроков, во время изучения алфавита. Так, заучивание новых букв и фонетическая отработка звуков могут происходить параллельно с отработкой и заучиванием названий музыкальных инструментов, демонстрируемых при помощи учебных карточек либо современных мультимедийных устройств. Многие синологи выявляют 
у представителей китайского этнотипа неразвитость абстрактного мышления и полагают, что «китайцы в процессе мышления предпочитают использовать правое полушарие» [15, с. 98], в котором преобладает интуитивное, художественное начало. Именно поэтому на уроках русского языка как иностранного при работе с китайской группой студентов необходимо давать больше наглядного материала, активно использовать для работы доску, показывать различные иллюстрации, цветные карточки, фотографии на компьютере, чтобы активизировать зрительный канал восприятия, который зачастую является ведущим в данном этническом коллективе. Кроме того, студенты-музыканты относятся к творческому типу личности, а «творчески мыслящие люди отличаются от людей, способных только усваивать знания и выполнять привычную, хорошо налаженную работу, богатством внутренних переживаний, их тонкостью и глубиной» [11, с. 77].

Для формирования фонетических навыков целесообразно давать следующие фонетические упражнения: чтение музыкальных терминов по ритмичным моделям; расстановка правильного ударения в словах; фонетические диктанты; тренировка парных звонких и глухих согласных и т.д. Известно, что для представителей китайского этнотипа особую сложность представляет произношение звука [р], поэтому для формирования правильной артикуляции целесообразно акцентировать внимание на таких лексических единицах, как: арфа, валторна, гитара, контрабас, барабан, кларнет, орган, тромбон, труба. В качестве «фонетической тренировки» [6, с. 19] можно использовать скороговорки: «Карл у Клары украл кораллы, а Клара у Карла украла кларнет»; «Гитаристы реверберировали, реверберировали, да не выреверберировали», «У Марфы нет арфы, у Митрофана - фортепиано, а у Федота - фагота». На дальнейшем этапе изучения возможно в качестве дополнительного фонетического и грамматического материала использование скороговорки с более сложной синтаксической конструкцией: «Дружно в оркестре играли дети: Карл играл на черном кларнете, Кирилл - на валторне, на арфе - Алла, а на рояле Лара играла»; «Роман Кармен положил в карман роман Ромена Роллана и пошёл в “Ромэн” на “Кармен”» и т.д.

При обучении музыкальной лексике важно учитывать, что в лексико-семантической группе «Музыкальные инструменты» отсутствуют антонимы, паронимы и синонимы. Антонимия невозможна, так как «нельзя противопоставить название одного инструмента другому»; паронимия невозможна, так как «небольшое количество сходных по звучанию лексем незначительно различаются по значению»; синонимия невозможна, так как, к примеру, «некорректно назвать роялем пианино, потому что у этих инструментов разный принцип расположения струн, деки и механической части: у пианино они расположены вертикально, а у рояля - горизонтально» [7, с. 73]. Кроме того, в русской музыкальной терминологии огромный пласт лексики составляют заимствования из иностранных языков, преимущественно из итальянского: адажио, аккорд, анданте, ария, виолончель, квартет, квинтет, мандолина, маэстро, партитура, скерцо, солист, соната, фагот и многие другие.

Типы упражнений для усвоения профессионально ориентированной лексики могут быть совершенно разными и отличаться друг от друга в зависимости от целей и задач, которые ставит преподаватель в определенный момент. Это могут быть словообразовательные упражнения, лексические, грамматические.

\section{Словообразовательные упражнения:}

1. Прочитайте названия музыкальных инструментов. Напишите названия музыкальных профессий в мужском и женском роде. Используйте суффиксы -ист-/-к-, -ач-/-к-, -щик-/-щиц-.

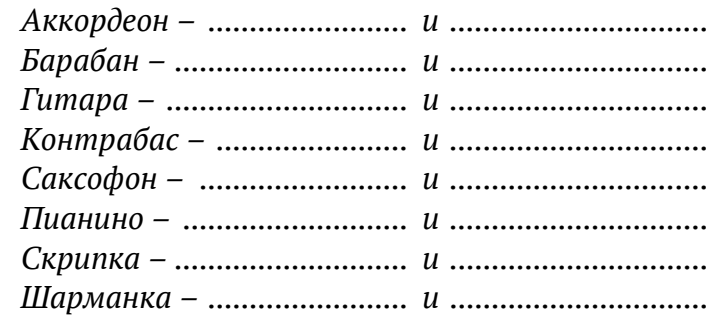

2. Упражнение противоположного типа: прочитайте названия музыкальных профессий, напишите названия музыкальных инструментов.

Пример: арфист - арфа, кларнетист - кларнет, скрипач - скрипка, трубач - труба и т.д.

Лексические упражнения:

1. Прочитайте слова, выберите из них музыкальные жанры. Напишите в тетради.

Слова для справок: валторна, адажио, дирижер, инструмент, оркестр, хип-хоп, романс, домра, тенор, минор, ударник, джаз, гамма, квартет, ансамбль, гимн, опера, оркестр, баллада, ритмика, балет, рок, интервал, мажор, бас, аллегро, ноктюрн, токатта, симфония.

2. Распределите по группам музыкальные инструменты.

\begin{tabular}{|c|c|c|c|}
\hline Духовые & Клавишные & Струнные & Ударные \\
\hline & & & \\
\hline
\end{tabular}

Слова для справок: аккордеон, флейта, гитара, гусли, дудук, барабан, бубен, гобой, фортепиано, лютня, эрху, синтезатор, гучжэн, шэн, труба, тромбон, банджо, изинху, губная гармошка, скрипка, балалайка, кларнет, виолончель, фагот.

3. Распределите по группам женские и мужские певческие голоса. Какие голоса являются низкими, средними и высокими?

\begin{tabular}{|c|c|}
\hline Женские & Мужские \\
\hline & \\
\hline
\end{tabular}


Слова для справок: контральто, бас, сопрано, баритон, меццо-сопрано, тенор.

4. Найдите лишнее слово. Модель: ларго, аллегро, фөртепиано, модерато, виво.

а) Чайковский, Рахманинов, Стравинский, Шостакович, Вивальди;

б) контрабас, гитара, саксофон, арфа, мандолина;

в) гусли, эрху, гучжэн, пипа, гуцинь.

Подобные упражнения представляют огромную пользу в плане отработки профессиональной лексики и тренировки памяти и логики студентов. Кроме того, можно познакомить китайских студентов и с музыкальными профессионализмами, используемыми русскими музыкантами в повседневном общении. К примеру, в компании гитаристов употребляются следующие слова: атака (сила ударов по струнам), басуха (бас-гитара), дрова (некачественная дешевая гитара), катавей (вырез в акустической гитаре), комбик (звукоусилитель), слухач (музыкант, который играет «на слух») и т.д. Важно сказать студентам, что данные слова изменяются по падежам, а после можно дать упражнения на составление простых предложений и на отработку предложно-падежной системы русского языка. Если первый тип упражнений направлен на отработку новой лексики, то второй тип упражнений ориентирован на закрепление новых слов и повторение предложно-падежной системы русского языка. Например:

Уменя есть басух_. (Именительный падеж)

У Сун Хао нет басух_. (Родительный падеж)

Кирилл радуется новой басух_. (Дательный падеж)

Иван купил басух_. (Винительный падеж)

Кирилл доволен басух. (Творительный падеж)

Антон играет на басух. (Предложный падеж)

Грамматические упражнения:

1. Распределите названия музыкальных инструментов в 3 колонки, соответствующие мужскому, женскому и среднему роду.

\begin{tabular}{|c|c|c|}
\hline Мужской род & Женский род & Средний род \\
\hline & & \\
\hline
\end{tabular}

Слова для справок: фагот, скрипка, виолончель, контрабас, барабан, гитара, фортепиано, флейта, банджо, варган, укулеле, кларнет, труба, рояль, гармошка, колокол, горн, балалайка, тромбон, гобой, валторна, зурна, орган, лира.

2. Вспомните предложный падеж (падеж 6) и употребление предлогов в/на.

a) Я играю ... (скрипка).

б) Ли Синхао учится ... (консерватория).

в) Вчера Фань Мэйлинь выступала ... (концерт) ... (зал) имени Рахманинова.

2) ... (урок) мы писали диктант.

д) Мой друг играет ... (гитара) и ... (банджо) известные песни.

е) Я хочу играть ... (флейта).

ё) Играть ... (иахматы) легче, чем ... (фортепиано).

ж) Ты любишь петь песни ... (хор)?

3. Прочитайте слова. Составьте предложения.

а) Моцарт, любить, играть, на, скрипка.

б) Анна, часто, петь, в, хор, и, выступать, на, сцена.

в) Я, любить, моя, гитара.

2) Антон, давно, мечтать, купить, кларнет.

д) Цзя Ижань, каждый, день, ездить, в, консерватория.

Формирование лингвистической компетенции - основная задача преподавателя русского языка как иностранного в музыкальном вузе, так как китайские студенты-музыканты проявляют интерес к русскому языку только в том случае, если они видят ценность и конструктивность полученных знаний, умений и навыков в профессиональной деятельности. Именно поэтому отработка профессиональных терминов может происходить посредством участия студентов в ролевых ситуативных играх («В театре», «На концерте», «В консерватории», «В филармонии»), а также во время выполнения подстановочных упражнений типа «прочитайте диалог, составьте аналогичный диалог». При этом новый диалог будет иметь иную лексическую наполненность. Пример:

a) «Сунь Сунхао, ты знаешь, куда завтра поедет Чжоу Юйцзюнь? - Чжоу Юйцзюнь? Конечно, знаю. Она завтра поедет в консерваторию на репетицию хора».

б) «Сунь Юй, ты кларнетист? - Да, я кларнетист»; «Чжан Ифан, ты арфистка? - Нет, я пианистка».

Совершенно иной тип упражнений - это чтение профессионально ориентированных текстов о русских и зарубежных композиторах и выполнение послетекстовых упражнений. Тексты, содержащие в себе подобную информацию, помогают заинтересовать китайских студентов-музыкантов, повысить познавательную мотивацию и закрепить тот или иной грамматический материал. Чтение способствует не только совершенствованию навыков понимания и восприятия текстов на изучаемом языке, но и овладению грамматическими конструкциями научного стиля речи, а также стимулированию учебно-познавательной мотивации. Но тем не менее, по словам С. Г. Тер-Минасовой, «узкоспециальным общением через письменные тексты отнюдь не исчерпывается владение языком как средством общения, средством коммуникации» [17, с. 33]. Именно поэтому важно комбинировать разные типы упражнений для того, чтобы подготовить иностранных студентов 
не только к чтению литературы по специальности на первом курсе, но и сделать их полноценными членами общества, способными грамотно говорить на русском языке, общаться в профессиональной среде, выражать свои мысли и желания.

В целом при разработке данного комплекса упражнений нами учитывались менталитет, культурные и психологические особенности китайского этноса, условия обучения и уровень языковой подготовки студентов-музыкантов из Китая. Все разработанные упражнения удачно сочетаются и дополняют друг друга, а также способствуют успешному усвоению китайскими студентами профессионально ориентированной лексики и формированию лингвистической компетенции. Важно учить китайских студентов не только говорить, но и мыслить на новом для них языке, раскрывая при этом внутренний творческий потенциал.

\section{Заключение}

Наше исследование показало, что при обучении китайских студентов на подготовительном факультете в музыкальном вузе особое внимание следует акцентировать на работе с музыкальной терминологией и способах её интегрирования в повседневную речь. Так, участие студентов в ролевых ситуативных играх, а также выполнение грамматических, лексических и словообразовательных упражнений позволяет не только сформировать лингвистическую компетенцию, но и довести навыки употребления музыкальных терминов до автоматизма, осмысления использования предложно-падежной системы русского языка, улучшения навыков словообразования, различения похожих словоформ и т.д.

Вместе с тем следует подчеркнуть, что на данном этапе развития методики преподавания русского языка как иностранного, требует решения актуальная проблема, связанная с практикой профессионально ориентированного обучения китайских студентов музыкального профиля. Кроме того, в настоящее время создано недостаточное количество научно-методических разработок для обучения языку специальности студентовмузыкантов из Китая. Считаем, что для оптимизации процесса подготовки китайских студентов музыкального профиля преподаватели по музыкальным дисциплинам должны консультировать преподавателей русского языка как иностранного и непосредственно участвовать при разработке научно-методических разработок по языку специальности. Только в таком случае качество обучения русскому языку как иностранному в музыкальных вузах России станет намного выше.

\section{Список источников}

1. Агафонова Н. А. Реализация поликультурного компонента профессионально-педагогической подготовки студентов ссуз музыкального профиля: дисс. ... к. пед. н. Казань, 2007. 199 с.

2. Балыхина Т. М., Чжао Ю. От методики к этнометодике. Обучение китайцев русскому языку: проблемы и пути их преодоления: монография. Изд-е 2-е. М.: РУДН, 2010. 344 с.

3. Березовский С. Б. Готовимся к профессиональному общению. О русской музыке, Гнесиных, Гнесинке, гнесинцах: учебное пособие для иностранных студентов. М.: Согласие, 2015. 144 с.

4. Борисова Е. Н., Глазкова Т. В. Профессиональное общение музыкантов. Диалог: учебно-методическое пособие по культуре речи для обучения студентов-музыкантов русскому языку как иностранному. М.: Согласие, 2015. 80 с.

5. Ван В. Музыкальный калейдоскоп: сборник тренировочных упражнений для иностранных (китайских) студентов Института искусств / науч. ред. В. Д. Янченко. М.: МПГУ, 2017. 130 с.

6. Верещагина Л. М. Русский язык для музыкантов: элементарный практический курс русского языка: учебник. М.: Русский язык. Курсы, 2014. 368 с.

7. Кудрин И. В. Системные отношения в лексико-семантической группе «музыкальные инструменты» (на материале современного русского языка) // Известия Волгоградского государственного педагогического университета. 2018. № 3 (126). С. 72-76.

8. Лазовская А. И., Тихоненко Е. В. Русский язык как иностранный: модуль профессионального владения. Музыкальное искусство: учебное пособие для иностранных студентов учреждений высшего образования по специальностям музыкального искусства. Мн.: РИВШ, 2012. 166 с.

9. Мансурова Г. И., Маркелов В. С. Иностранный (русский) язык в научно-профессиональной сфере. Естественно-научный профиль. Казань: Изд-во Казан. ун-та, 2012. 144 с.

10. Немченко Н. В. Развитие коммуникативной компетенции иностранных студентов в процессе профессионально-языковой подготовки в вузе культуры: дисс. ... к. пед. н. М., 2003. 346 с.

11. Петрушин В. И. Музыкальная психология: учебное пособие для вузов. Изд-е 2-е. М.: Академический Проект; Трикста, 2008. 400 с.

12. Пугачев И. А. Профессионально ориентированное обучение русскому языку как иностранному: теория, практика, технологии: монография. М.: РУДН, 2016. 483 с.

13. Рякина О. Р., Березовский С. Б. Русский язык как иностранный. Увертюра. М.: Согласие, 2018. 524 с.

14. Рякина О. Р., Березовский С. Б., Доброскокина Т. А. Mustermin.ru. Изучаем музыкальные термины: учебное пособие для иностранных студентов. М.: Согласие, 2015. 80 с. 
15. Спешнев Н. А. Китайцы: особенности национальной психологии. СПб.: КАРО, 2017. 336 с.

16. Степаненко В. А. Лингвометодическая модель обучения коммуникации с учетом сертификации уровней владения русским языком как иностранным: дисс. ... д. пед. н. М., 2008. 336 с.

17. Тер-Минасова С. Г. Язык и межкультурная коммуникация. М.: МГУ, 2008. 352 с.

18. Хонг Е. Ю. Читаем и говорим о музыке: учебное пособие для иностранных студентов музыкальных факультетов продвинутого и завершающего этапов обучения. M.: GtPrint, 2013. 72 с.

19. Чжао Ю. Лингводидактические основы этноориентированного обучения русскому языку и тестирования: на примере китайских учащихся: дисс. ... к. пед. н. М., 2008. 291 с.

20. Шукин А. Н. Методика преподавания русского языка как иностранного: учеб. пособие для вузов. М.: Высш. шк., 2003. 334 c.

21. Yusupova Z. F. Dialogue of Cultures of Teaching of Russian as a Foreign Language in the Chinese Audience: Approaches and Solutions // Ifte 2016 - 2nd International Forum on Teacher Education. 2016. Vol. 12. P. 203-207.

\section{Информация об авторах | Author information}

\section{RU Забуга Антонина Александровна ${ }^{1}$}

${ }^{1}$ Казанский (Приволжский) федеральный университет

EN Zabuga Antonina Aleksandrovna

${ }^{1}$ Kazan (Volga Region) Federal University

${ }^{1}$ antonina.zabuga@mail.ru

\section{Информация о статье | About this article}

Дата поступления рукописи (received): 25.05.2020; опубликовано (published): 30.12.2020.

Ключевые слова (keywords): русский язык как иностранный; китайские студенты-музыканты; язык специальности; музыкальная лексика; комплекс упражнений; Russian as a foreign language; students-musicians from China; professional language; musical vocabulary; set of exercises. 